\title{
CHARACTERIZATION OF AEROSOL SIZE AND MICROPHYSICAL PROPERTIES FROM MULTI-WAVELENGTH RAMAN LIDAR MEASUREMENTS: INTER-COMPARISON WITH IN SITU SENSORS ONBOARD THE ATR 42 IN THE FRAMEWORK OF HYMEX-SOP1 Benedetto De Rosa $^{1}$, Paolo Di Girolamo ${ }^{1}$, Donato Summa ${ }^{1}$ Dario Stellitano ${ }^{1}$ \\ ${ }^{1}$ Scuola di Ingegneria, Università degli Studi della Basilicata, Potenza, 85100, Italy *Email: bundit@hotmail.it
}

\begin{abstract}
This extended abstract reports measurements that were carried out by the Raman lidar system BASIL in the frame of the Hydrological Cycle in the Mediterranean Experiment - Special Observation Period 1 (HyMeX-SOP1). A specific case study was selected revealing the presence of variable aerosol properties at different altitudes. Specifically, Raman lidar measurements on 02 October 2012 reveal the presence of two distinct aerosol layers, a lower one extending up to $\sim 3 \mathrm{~km}$ and an upper one extending from $3.5 \mathrm{~km}$ to 4.7 $\mathrm{km}$. Aerosol and size microphysical properties are determined from multi-wavelength measurements of particle backscattering and extinction profiles based on the application of a retrieval scheme which employs Tikhonov's inversion with regularization. Inversion results suggest a size distribution with the presence, in both the lower and upper aerosol layer, of two particle modes (a fine mode, with a radius of $\sim 0.2 \mu \mathrm{m}$, and a coarse mode, with radii in the range $2-4 \mu \mathrm{m}$ ), volume concentration values of $2-4 \mathrm{~mm}^{3} \mathrm{~cm}^{-3}$ and effective radii in the range $0.2-0.6 \mu \mathrm{m}$.

This effort benefited from the dedicated flights of the French research aircraft ATR42, equipped with a variety of in situ sensors for measuring aerosol/cloud size and microphysical properties. Aerosol size and microphysical properties retrieved from multi-wavelength Raman lidar measurements were compared with simultaneous and co-located in-situ measurements.
\end{abstract}

\section{INTRODUCTION}

Tropospheric aerosols are a fundamental atmospheric component of the Earth's radiation budget. Increased aerosol concentrations intensify atmospheric scattering and absorption processes for both solar and planetary radiation. Additionally, increased tropospheric aerosol concentrations may lead to enhanced nucleation and intensified cloud formation processes The above mentioned direct and indirect aerosol effect have a strong impact on the Earth's radiation budget. A quantitative assessment of these effects is difficult to obtain and estimates are typically affected by large uncertainties.

Despite the recognized importance of having vertically resolved measurements of aerosol size and microphysical properties, a limited number of techniques can provide this information..

Airborne in situ sensors may be effective. However, their exploitation is complex and costly, and consequently their use is limited. Remote sensing techniques have strong potential, but their applicability and the reliability of results from need to be verified against independent measurements. Among others, multi-wavelength Raman lidar measurements appear to be very promising. The dataset reported and discussed in the present research effort represents a unique opportunity to verify the quality of the results in terms of size and microphysical properties obtained through the application of obtained the retrieval scheme based on Tikhonov's inversion with regularization.

Reported measurements were carried out in the frame of HyMeX-SOP1, which took place in the period September-November 2012 over the North-Western Mediterranean Sea and its surrounding coastal regions in France, Italy and Spain. In the frame of HyMeX-SOP1, the University of BASILicata ground-based Raman Lidar system (BASIL) was deployed in the Cévennes-Vivarais site (Candillargues, Southern France, Lat: $43^{\circ} 37^{\prime} \mathrm{N}$, Long: $4^{\circ} 4^{\prime} \mathrm{E}$, Elev: $1 \mathrm{~m}$ ). 
As part of HyMeX-SOP1, HyMeX-SOP1 the French research aircraft ATR42, equipped with a variety of in situ sensors for turbulence and aerosol/cloud microphysical measurements, performed more than 60 flight hours, 8 of which as part of the EUFAR project "WaLiTemp. A specific flight pattern was defined for this project, with the aircraft making spirals up and down around a central location, originally aimed to be the atmospheric supersite in Candillargues, but, because of air-traffic restrictions, $20 \mathrm{~km}$ eastward of the supersite.

\section{METHODOLOGY}

\subsection{The lidar system}

The lidar transmitter is developed around a $\mathrm{Nd}$ :YAG laser source, including both second and third harmonic generation crystals.. Laser pulses at 1064, 532 and $355 \mathrm{~nm}$ are simultaneously transmitted in the atmosphere along the zenith. BASIL is capable to perform high-resolution and accurate measurements of atmospheric water vapour and temperature, both in daytime and night-time, based on the application of the vibrational and rotational Raman lidar techniques, respectively, in the UV [1, 2, 3, 4, 5]. Besides water vapour and temperature, BASIL, in its HyMeX configuration, also performed measurements of the particle backscattering coefficient at $355,532 \mathrm{~nm}$ and 1064 of the particle extinction coefficient at $355 \mathrm{~nm}$ and 532, and of particle depolarization at $355 \mathrm{~nm}$. In addition to HyMeX-SOP1, BASIL has been deployed in several international field campaigns [6-9].

A retrieval algorithm, exploiting Tikhonov's inversion with regularization, is applied to multiwavelength particle backscattering and extinction measurements in order to retrieve particle size and microphysical parameters. The retrieval scheme makes use of kernel functions for spherical particles. Veselovskii et al. [10-11] demonstrated that an input data set consisting of particle backscattering coefficient profiles at 355, 532 and $1064 \mathrm{~nm}$ and particle extinction coefficient at 355 and 532 is sufficient to allow retrieving specific aerosol size and microphysical parameters, such as number, surface, volume density, effective radius and complex refractive index. In order form this to be possible the statistical uncertainty affecting particle backscatter measurements must not exceed $5 \%$, while the uncertainty affecting particle extinction measurements must not exceed $10 \%[10-11]$.

\section{RESULTS}

\subsection{Case of study 2 October 2012}

We have focused our attention on the case study on 2 October 2012. The color map in figure 1 illustrates the time evolution of particle backscattering coefficient at $355 \mathrm{~nm}$ covering a period of approx. $4 \mathrm{~h}$ from 19:20 to 23:40 UTC. On this day the ATR 42 flew from 19:20 to 22:20 UTC.

For the purpose of retrieving particle size distribution parameters as a function of altitude, we focused on a time interval when aerosol concentration was higher. In order to get high enough signals-to-noise ratios, and consequently low statistical uncertainty, for the retrieval scheme to be applicable, we considered a 2-h averaging for both particle backscattering and extinction coefficient, i.e. the time interval from 20:30 to 22:30 UTC.

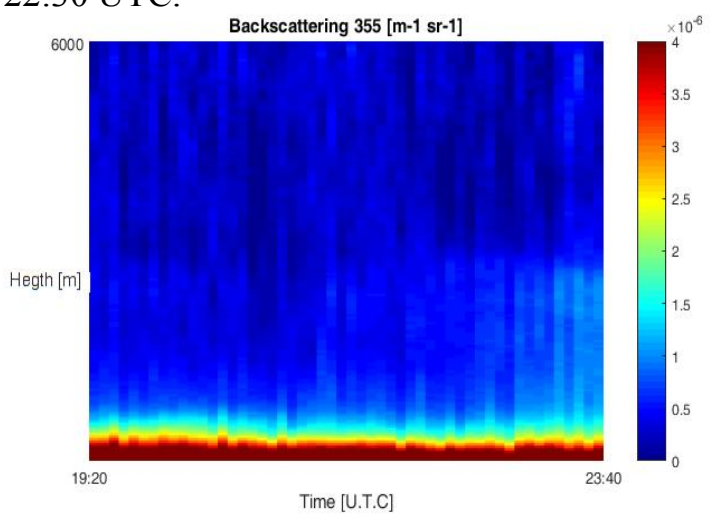

Fig.1 Time evolution of the backscattering coefficient at $355 \mathrm{~nm}$ in the time interval 19:20-23:40 UTC on 2 October 2012.

Figure 2 shows the 5-days back-trajectory analysis as determined with NOAA Lagrangian backtrajectory model HYSPLIT. The analysis reveals that air masses reaching the measurement site at an altitude of $600 \mathrm{~m}$ were originated over the Northern Atlantic Ocean, South of Iceland, and passed at low altitudes $(500-600 \mathrm{~m})$ over continental areas with high anthropic impact (Ireland, England and Northern France). The chemical sensors onboard the ATR 42 show high concentration values for $\mathrm{NO}_{3} \quad \mathrm{SO}_{4} \quad \mathrm{NH}_{4}$, which are typical of a polluted aerosol (figure 3 ). 
The back-trajectory analysis also reveals that air masses at $4000 \mathrm{~m}$ were originated over the Northern Atlantic Ocean, off-shore the Canadian coast, and overpassed the Northern coast of Spain before reaching the measurement site. This is a marine aerosol, with a high concentration of sulfates.

Both particle backscattering and extinction coefficient profiles, shown in figure 4, reveal the presence of the two different aerosol layers. The lower polluted layer extends up to $\sim 3 \mathrm{~km}$, while the upper marine layer extends from 3.5 to $4.7 \mathrm{~km}$. To reduce the statistical noise the backscattering coefficient was determined with a vertical resolution of $300 \mathrm{~m}$, while the extinction coefficient with a vertical resolution of $600 \mathrm{~m}$. The backscatter coefficient at 355 and 532 was determined based on the application of the Raman technique, while at 1064 the Klett-modified method was applied [12-13]. The extinction at both 355 and $532 \mathrm{~nm}$ was calculated using the approach proposed by Ansmann [14].

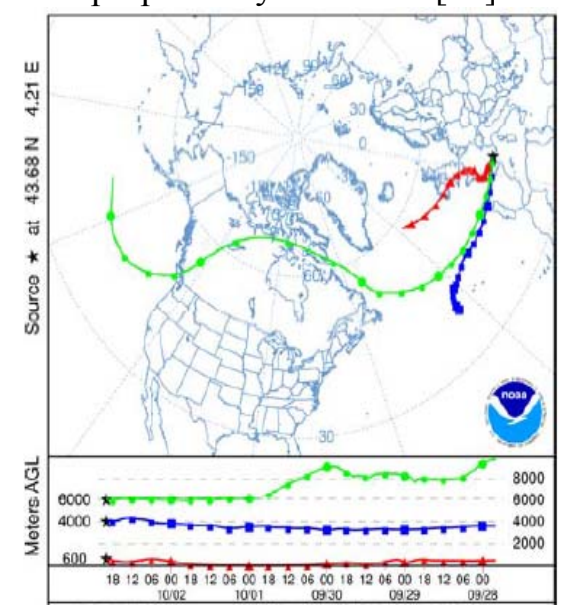

Figure 2 Back-trajectory analysis as determined with NOAA HYSPLIT model. The three illustrated trajectories are those ending over the lidar site at $600 \mathrm{~m}$, $4000 \mathrm{~m}$ and $6000 \mathrm{~m}$ (in red, blue and green, respectively) at 20:00 UTC on 2 October 2012.

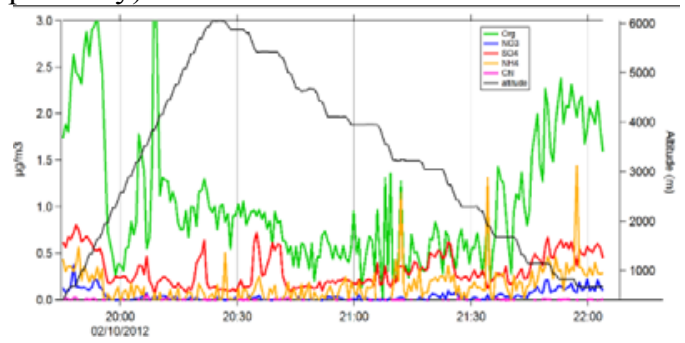

Figure 3: Measurements carried out by the chemical sensors on board the ATR 42.

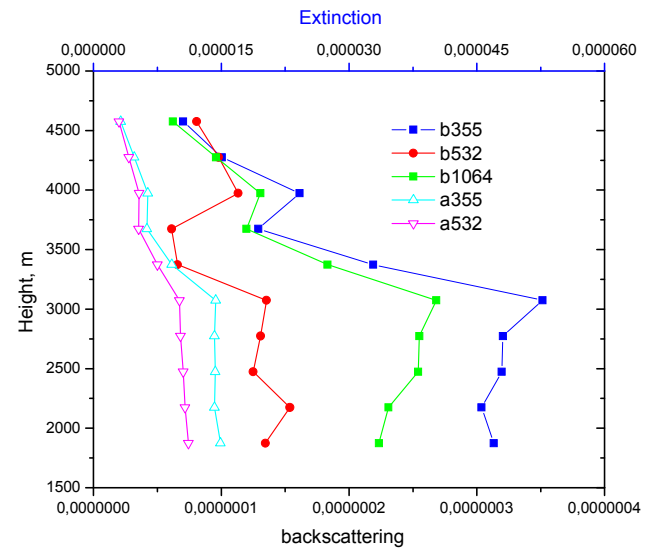

Figure 4: Vertical profile of the backscattering coefficient at 355, 532 and $1064 \mathrm{~nm}$ and the extinction coefficient at 355 and $532 \mathrm{~nm}$.

Aerosol size and microphysical properties obtained from the multi-wavelength Raman lidar data based on the application of the above mentioned inversion algorithm are compared with those simultaneously measured from in-situ sensors on-board the ATR42. Figure 5 illustrates the comparison expressed in terms of volume concentration measurements, with the two instruments showing similar values both in the lower (2-4 $\mathrm{mm}^{3} \mathrm{~cm}^{-3}$ for the Raman lidar and 2-5 $\mathrm{mm}^{3} \mathrm{~cm}^{-3}$ for the in-situ sensors) and upper layer (2-3 $\mathrm{mm}^{3} \mathrm{~cm}^{-3}$ for the Raman lidar and 1-3.5 $\mathrm{mm}^{3} \mathrm{~cm}^{-3}$ for the in-situ sensors).

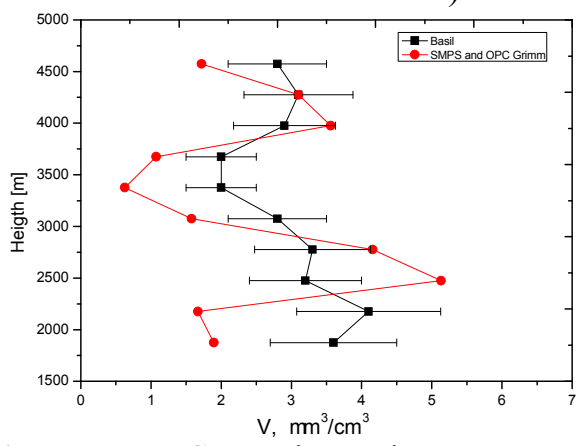

Figure 5: Comparison in terms of volume concentration measurements between BASIL and the on-board in situ sensors.

Figure 6 shows the variability with altitude of the effective radius, with values in the range 0.2-0.6 $\mu \mathrm{m}$. The agreement between BASIL and the insitu sensors is good at all altitudes, with values measured by the in-situ sensors always within the error bar of the corresponding measurements by the Raman lidar, with the only exception of the values at $\sim 4 \mathrm{~km}$. As expected, values in the upper 
layer are slightly larger than those in the lower layer, as in fact marine aerosols are typically larger than urban continental aerosols.

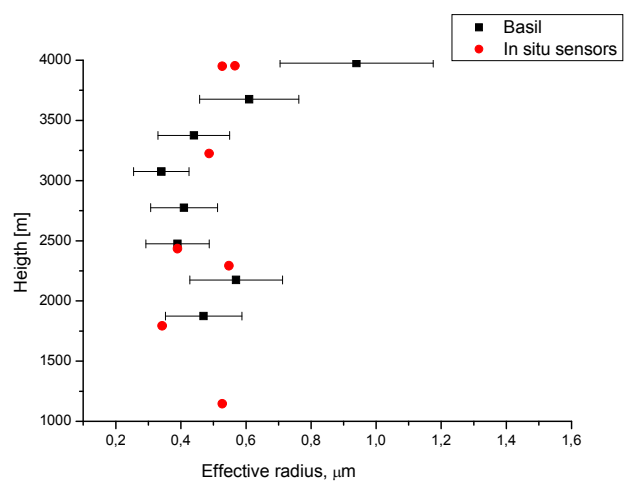

Figure 6: Comparison in terms of effective radius measurements between BASIL and the on-board in situ sensors.

Figures 7,8 and 9 show the aerosol size distribution at 2, 2.7 and $4 \mathrm{~km}$. The agreement between Raman lidar and in-situ sensors is good at all altitudes. It is to be specified that the in-situ sensors are not sensitivity to particle with diameters in excess of $2 \mu \mathrm{m}$.

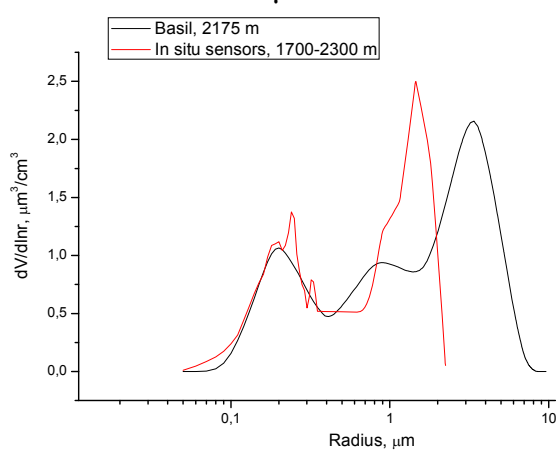

Figure 7: Comparison in terms of size distribution at $2175 \mathrm{~m}$ measurements between BASIL and the onboard in situ sensors.

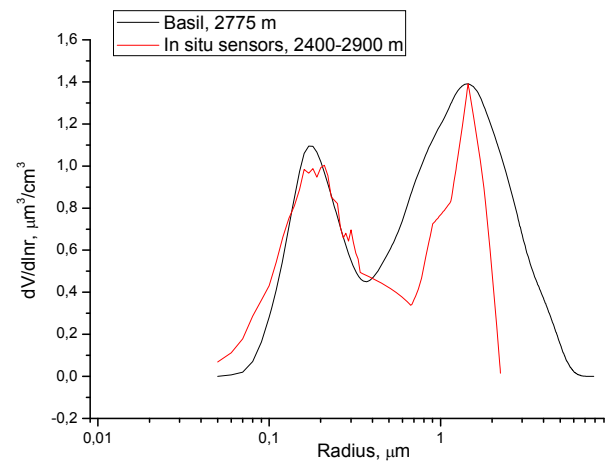

Figure 8: Comparison in terms of size distribution at 2775 m measurements between BASIL and the onboard in situ sensors.

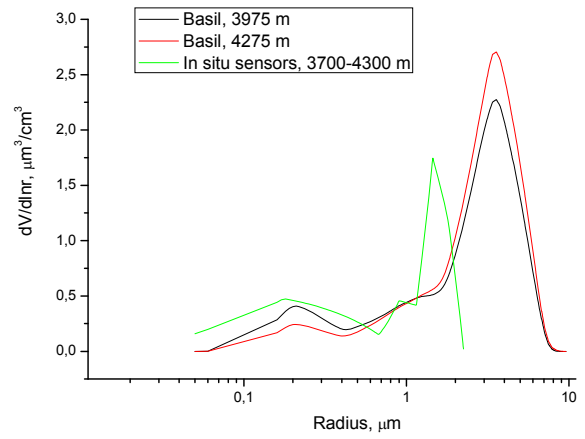

Figure 9: Comparison in terms of size distribution at $3975 \mathrm{~m}$ measurements between BASIL and the onboard in situ sensors.

At 2 and $2.7 \mathrm{~km}$ the size distribution is dominated by the continental aerosols, while at $4 \mathrm{~km}$ most aerosols have a marine origin and have crossed the Atlantic before reaching the site.

\section{REFERENCES}

[1] A. Behrendt, J. Reichardt, Appl. Optics 39, 13721378, doi: 10.1364/AO.39.001372 (2000).

[2] P. Di Girolamo, et al. Geophys. Res. Lett., 31, doi: 10.1029/2003GL018342 (2004).

[3] P. Di Girolamo, et al. Appl. Opt. 45, 2474-2494, doi:10.1364/AO.45.002474 (2006).

[4] R. Bhawar, et al. Quarterly Journal of the Royal Meteorological Society 137, 325-348, doi: 10.1002/qj.697 (2011).

[5] A. Behrendt, Weitkamp, C., Springer, New York, (2005).

[6] R. Bhawar, et al. Geophysical Research Letters 35, L04812, doi: 10.1029/2007GL032207 (2008).

[7] C. Serio, et al. Optics Express 16/20, 15816-15833, doi: 10.1364/OE.16.015816 (2008).

[8] N. Kalthoff, et al. Atmospheric Research 93, 680694, doi: 10.1016/j.atmosres.2009.02.010 (2009).

[9] A. Macke, et al. Atmos. Chem. Phys. 17, 48874914, doi:10.5194/acp-17-4887-2017 (2017).

[10] I. Veselovskii, et al. Inversion with regularization for the retrieval of tropospheric aerosol parameters from multiwavelength lidar sounding, Appl. Opt., AO, 41, 3685-3699, doi:10.1364/AO.41.003685 (2002).

[11] I. Veselovskii, et al. J. Geophys. Res., 115, D21203, doi: 10.1029/2010JD014139, (2010).

[12] P. Di Girolamo, et al. Journal of Aerosol Science 26, 989-1001, doi: 10.1016/0021-8502(95)00025-8 (1995).

[13] P. Di Girolamo, et al. Appl. Opt 38(21), 45854595, doi: 10.1364/AO.38.004585 (1999).

[14] A. Ansmann, et al. Measurement of atmospheric aerosol extinction profiles with a Raman lidar, Opt. Lett., OL, 15(13), 746-748, doi:10.1364/OL.15.000746 (1990). 